\title{
PERILAKU MENGGARAM GAJAH SUMATERA (Elephas maximus sumatranus) DAN KANDUNGAN GARAM MINERAL PADA SALTLICKS DI RESORT PEMERIHAN TAMAN NASIONAL BUKIT BARISAN SELATAN
}

\author{
(SALTING BEHAVIOR OF SUMATRAN ELEPHANTS (Elephas maximus \\ sumatranus) AND MINERAL SALT CONTENT ON SALTLICKS IN PEMERIHAN \\ RESORT BUKIT BARISAN SELATAN NATIONAL PARK)
}

\author{
Dea Andhari Resphaty ${ }^{1)}$, Sugeng P. Harianto ${ }^{2)}$, dan Bainah Sari Dewi ${ }^{2)}$ \\ ${ }^{1)}$ Mahasiswa Jurusan Kehutanan Fakultas Pertanian Universitas Lampung, \\ ${ }^{2)}$ Staf Pengajar Jurusan Kehutanan Fakultas Pertanian Universitas Lampung, \\ Jurusan Kehutanan Fakultas Pertanian Universitas Lampung \\ J1. Soemantri Brojonegoro No. 1 Bandar Lampung, 35145 \\ Email: resphaty94@gmail.com \\ Phone: 081271661232
}

\begin{abstract}
ABSTRAK
Gajah sumatera (Elephas maximus sumatranus) membutuhkan garam mineral untuk proses metabolisme tubuh yang dapat diperoleh dari vegetasi tumbuhan pakan. Kekurangan mineral pada tumbuhan pakan menyebabkan gajah mencari sumber alternatif lain seperti menjilat dan memakan tanah yang mengandung garam. Sedikitnya informasi mengenai perilaku menggaram, dan kandungan garam mineral di tempat gajah menggaram menyebabkan penelitian ini penting dilakukan. Tujuan penelitian ini untuk menganalisis perilaku menggaram gajah sumatera, dan mengetahui kandungan garam mineral tanah di tempat gajah menggaram. Penelitian dilaksanakan pada Januari 2015 di Resort Pemerihan TNBBS. Metode penelitian menggunakan analisis deskriptif, dan Microwafe Plasma-Atomic Emission Spectrometer (MP-AES) untuk analisis kandungan garam serta didukung wawancara key person, dan studi literatur. Hasil penelitian menunjukkan perilaku menggaram Yongki $(0,08 \%)$ dari total perilaku harian. Sumber garam berasal dari tanah dan lumpur di pinggir sungai, tebing, hutan primer, hutan sekunder, dan padang rumput. Menggaram dilakukan dengan cara mengambil tanah, dan lumpur secara langsung dengan belalai, dan dimasukkan ke dalam mulut. Jumlah garam mineral yang terkandung pada sample tanah yaitu $\mathrm{Ca}$ (0,190\%), Mg (0,013\%), K (0,158\%). Pada lumpur Ca (0.323\%), Mg (0,405\%), K (0,233\%). Gajah sering menggunakan lumpur untuk menggaram karena kandungan mineralnya lebih tinggi dibanding tanah.
\end{abstract}

Kata kunci: Gajah sumatera, perilaku menggaram, saltlicks, kandungan garam mineral tanah, Taman Nasional Bukit Barisan Selatan

\section{ABSTRACT}

Sumatran elephant (Elephas maximus sumatranus) requires mineral salts to the body's metabolic processes which can be obtained from the vegetation feed. Mineral deficiencies in plants causes elephants seek other alternative sources such as lick and eat soil that contains salt. This research was done due to lack information about salting behavior and mineral salt content in the salticks. The aims of these research were to analyze the salting behavior of Sumatran elephants and to find out mineral salt content of the soil in the saltlicks. The research was done on January 2015 in TNBBS Pemerihan Resort. The research methods of salting behavior used descriptive analysis, mineral content analysis used Microwafe PlasmaAtomic Emission Spectrometer (MP-AES) supported by key person interview and literature 
studies. The results of this study indicate that salting behavior of Yongki (0,08\%) of total daily behavior, the source of salt obtained from soil and mud on riparian, cliffs, primary forest, secondary forest and meadow. Salting was done by taking directly using trunk and put into the mouth. The results of the analyzed of mineral salt content in the soil there are Ca (0.190\%), Mg (0,013\%), K (0.158\%). In the mud Ca (0,323\%), $\mathrm{Mg}(0.405 \%)$ and $\mathrm{K}$ (0.233\%). Elephant more prefer to the mud because mineral content in the mud is higher than soil.

Keywords: $\quad$ Sumatran elephants, salting behavior, saltlicks, mineral salt content of the soil, Bukit Barisan Selatan National Park

\section{PENDAHULUAN}

Gajah merupakan satwa herbivora (pemakan tumbuhan) yang memerlukan asupan nutrisi, dan mineral untuk menjalankan aktivitas menjelajah. Menurut Lameed dan Adetola (2012) Gajah sering mengunjungi saltlicks (tempat menggaram) untuk mencari garam mineral. Menggaram dilakukan secara alami untuk mencari nutrisi yang sangat penting untuk kelangsungan hidupnya (Komers, Messier, dan Gates, 1992). Garam mineral merupakan salah satu persyaratan hidup gajah yang mutlak harus tersedia (Lekagul dan McNeely, 1977). Kebutuhan mineral dipengaruhi oleh beberapa faktor termasuk reproduksi, umur, jenis kelamin, tingkat pertumbuhan, dan kondisi fisiologis (Sitienei, Jiwen, Ngene, De la paix, dan Waweru, 2011).

Garam mineral yang dibutuhkan oleh gajah antara lain: kalsium, magnesium, dan kalium (Shoshani dan Eisenberg, 1982). Mineral tersebut merupakan unsur makro yang diperlukan tubuh dalam jumlah yang banyak. Kecenderungan gajah memakan tanah dilakukan untuk mencukupi kebutuhan mineral yang tidak diperoleh dari hijauan pakan. Menurut Shoshani dan Eisenberg (1982) gajah mencari garam dengan menjilat-jilat benda dan apapun yang mengandung garam dengan belalainya. Ketersediaan saltlicks di daerah jelajah gajah sangat menentukan tingkat kesejahteraan satwa ini sehingga informasi mengenai kandungan garam dalam tanah sangat diperlukan (Ribai, Setiawan, dan Darmawan, 2012).

Tujuan penelitian ini untuk menganalisis perilaku menggaram gajah serta mengetahui kandungan garam mineral di tanah tempat gajah menggaram di Resort Pemerihan TNBBS.

\section{METODE PENELITIAN}

Penelitian dilaksanakan pada bulan Januari 2015 di Resort Pemerihan TNBBS. alat yang digunakan yaitu: kantong plastik, Global Position System (GPS), kamera, jam tangan, alat tulis, dan tally sheet. Objek penelitian yang diamati yaitu dua ekor gajah sumatera jantan (Yongki) dan betina (Arni) serta sampel tanah yang mengandung garam mineral. Data yang dikumpulkan yaitu data primer mengenai perilaku menggaram gajah yang meliputi: cara menggaram, lokasi menggaram, sumber garam, dan waktu menggaram serta sampel tanah yang mengandung garam mineral.

Perilaku menggaram gajah diperoleh dari pengamatan secara deskriptif, dan wawancara terhadap mahout gajah, dan kandungan garam dalam tanah diperoleh secara observasi dengan mengambil sampel tanah yang dijadikan sumber garam oleh gajah sumatera secara komposit. Sampel tanah komposit adalah campuran beberapa tanah individu atau gabungan sampel tanah dari lokasi pengambilan yang berbeda (Turang, Moningka, Kumontoi, dan Sudarti, 2013).

Sampel tanah dianalisis di laboratorium Fakultas Matematikan, dan Ilmu Pengetahuan Alam (MIPA) Universitas Lampung menggunakan metode Microwafe Plasma-Atomic 
Emission Spectrometer (MP-AES) yaitu metode untuk menganalisis kandungan unsur pada larutan (Drvodelic dan Cauduro, 2013). Pengumpulan data sekunder diperoleh dari studi literatur. Lokasi pengambilan sampel tanah di tempat gajah menggaram dideskripsikan pada Gambar 1.

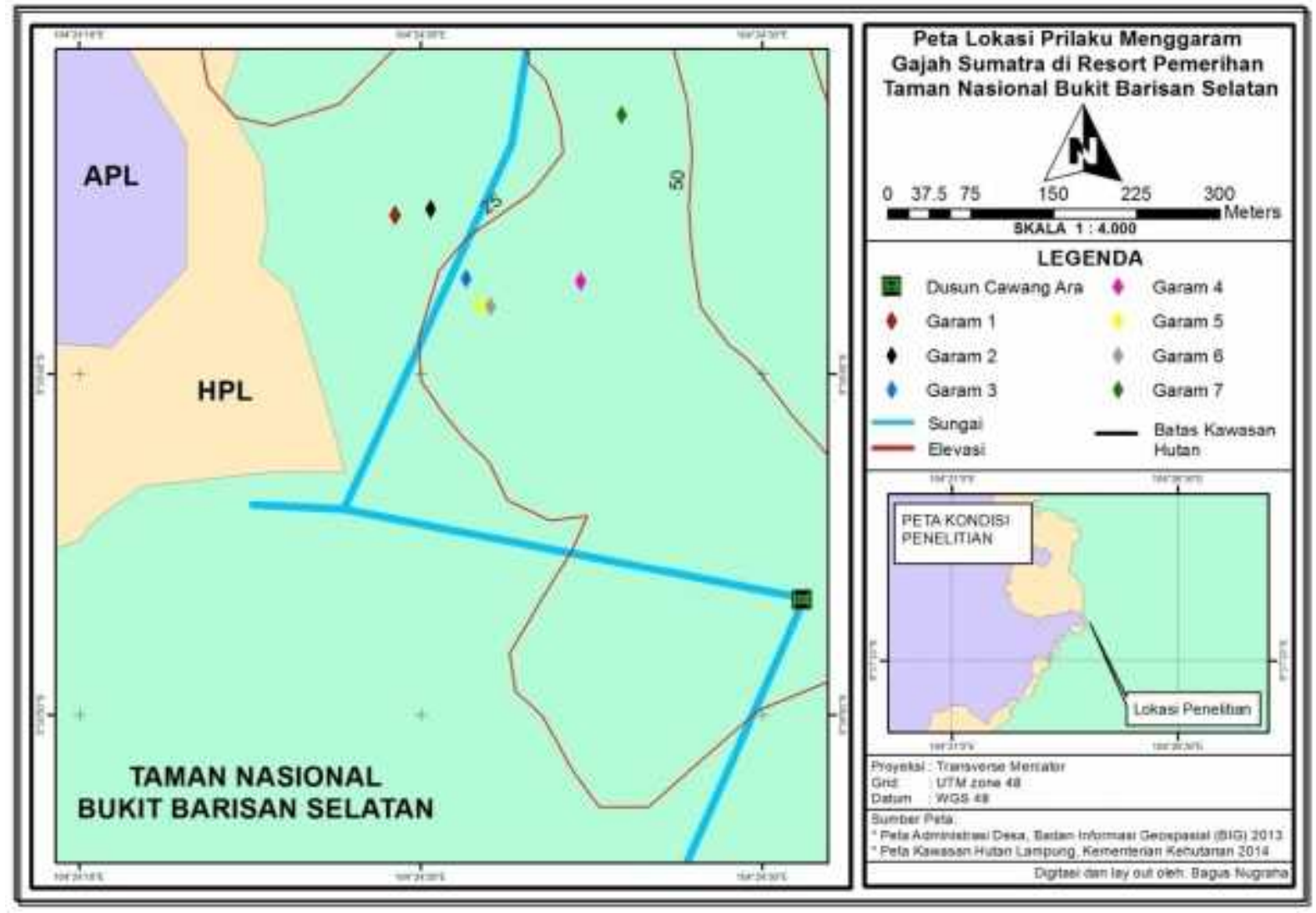

Gambar 1. Peta lokasi menggaram gajah pada penelitian perilaku menggaram gajah sumatera (Elephas maximus sumatranus) dan kandungan garam mineral pada saltlicks di resort pemerihan TNBBS 2015 skala 1:4000 (Sumber: Nugraha dan Resphaty, 2015)

\section{HASIL DAN PEMBAHASAN}

\section{A. Perilaku Menggaram}

Kekurangan garam mineral pada tanaman yang dimakan oleh satwa liar menyebabkan satwa menggaram secara alami dengan mencari sumber lain seperti memakan dan menjilati tanah di hutan atau lokasi tertentu (Ayeni, 1972). Menurut Wari (1993) dalam Lameed dan Adetola (2012) gajah mampu melakukan perjalanan jarak jauh untuk mengunjungi tempat menggaram, dan mengkonsumsi garam mineral dalam jumlah banyak sebagai pencahar. Gajah melakukan aktivitas menggaram saat merasa tubuhnya tidak sehat. Menurut Ribai dkk (2012) kondisi kesehatan gajah sumatera berpengaruh terhadap frekuensi menggaram.

Selama penelitian gajah betina (Arni) tidak menggaram sedangkan Yongki menggaram sebanyak 4 kali di hutan primer, pinggir sungai, dan padang rumput. Menurut Ribai dkk (2012) lokasi menggaram gajah di TNWK terdiri dari rawa, tebing, kubangan, jalan, dan padang rumput. Fadillah, Yoza, dan Sribudiani (2014) menyebutkan bahwa gajah juga mengunjungi lahan perkebunan sebagai tempat mencari sumber garam yang berupa galian dan penggemburan tanah diduga menggunakan gading dan dibantu dengan kaki.

Gajah menggaram pada saat cuaca hujan dan mendung, hal ini sesuai dengan pernyataan (Leckagul dan Mcneely, 1977) gajah mengunjungi tempat-tempat tertentu yang 
disebut dengan salt lick terutama pada saat atau sesudah hujan. Garam mineral seperti $\mathrm{Ca}, \mathrm{Mg}$ dan K dapat diperoleh dari sumbernya seperti tanah, lumpur, air, akar pohon atau kulit kayu, Akar pohon dan kulit kayu berfungsi sebagai jaringan pengangkut air dan garam mineral dari dalam tanah ke seluruh tubuh tumbuhan sehingga sering digunakan gajah sebagai sumber garam mineral. Menurut Rode, Chiyo, Chapman, dan Mcdowell (2006) kayu memiliki kadar kalsium tinggi (1.8-5.7\%). Batang kayu (cambium) juga dimakan untuk memenuhi mineral terutama kalsium untuk memperkuat tulang, gigi, dan gading yang terus tumbuh (Abdullah, Dahlian, dan Mukhlisin, 2009).

Gajah yang ada di Resort Pemerihan memilih sumber garam berupa lumpur, tanah, akar pohon, dan kulit kayu. Tanah yang ikut terangkut bersama akar saat gajah mencabut tanaman juga diduga mengandung garam mineral sehingga gajah jarang melakukan menggaram. Gajah menyukai tumbuhan berduri seperti ki kerbau, rotan, terong duri, dan putri malu untuk melukai bagian mulutnya sehingga mengeluarkan darah. Menurut hasil wawancara gajah melukai mulutnya dengan memakan batang bambu yang tajam kemudian mengecap ngecap darah yang keluar (Anton, 2015 Prescom). Hal ini sesuai dengan pernyataan Hariyanto (2009) yang menyebutkan bahwa gajah sering melukai bagian tubuhnya untuk menyikat darah yang mengandung garam. Menggaram dilakukan secara alami dan tidak pernah dilakukan pemberian garam mineral tambahan oleh mahout gajah seperti di Bali Safari and Marine Park (BSMP) pemenuhan kebutuhan garam mineral pada gajah dilakukan dengan cara menaburkan garam pada pakan gajah sehingga gajah hanya sesekali terlihat menggali tanah untuk menggaram (Yudarini, Soma, dan Widyastuti, 2013). Menurut Mahanani, Hendrarto, dan Soeprobowati (2012) di Pusat Latihan Gajah (PLG) untuk mencukupi kebutuhan garam mineral pakan ditambahi dengan garam dapur, gula, dan cuka.

Gajah jantan (Yongki) menggaram dengan cara mengendus sumber garam lalu mengambil sedikit tanah atau lumpur dengan belalai, kemudian dimasukkan kedalam mulut. Menurut wawancara terhadap mahout biasanya gajah betina (Arni) mengambil tanah dengan cara menggali dengan kaki depannya kemudian dimakan. Sedangkan Yongki pernah terlihat menusuk-nusukkan gading ke dinding sungai atau tebing sehingga tanah yang ada di dinding tersebut menjadi gembur kemudian digempalkan dengan belalai lalu dimakan (Sumarni, 2015 Prescom). Menurut Ribai dkk (2012) gajah cukup menggunakan belalai untuk mengambil tanah lunak, seperti di rawa, kubangan, dan jalan, sedangkan pada tanah keras gajah menggunakan gading untuk menghancurkannya, dan kakinya untuk mengaisnya terlebih dahulu. Gajah yang ada di BSMP menggaram dengan cara menggemburkan tanah dengan salah satu kaki depannya, kemudian menggambil tanah menggunakan belalai dan dimasukkan ke dalam mulut (Yudarini dkk, 2013). Menurut Leckagul dan Mcneely (1977) gajah yang bergading akan menusuk / menggali dinding saltlick dengan gading, atau bagi yang tidak bergading dengan cara menggaruk-nggaruk tanah dengan kaki, dan belalainya atau dengan menumbuk/mendobraknya.

\section{B. Kandungan Garam Mineral}

Sampel tanah dan lumpur yang digunakan untuk analisis kandungan garam diperoleh secara komposit dari 7 titik di berbagai lokasi saltlicks seperti (1) hutan primer, (2) hutan sekunder, (3) padang rumput, (4) tebing (dua titik), dan (5) pinggir sungai (dua titik).

Sampel tanah yang berasal dari lokasi menggaram gajah diperoleh berdasarkan observasi di lapangan, dan menurut wawancara terhadap mahout. Hasil analisis kandungan garam mineral tanah, dan lumpur yang dikonsumsi gajah sumatera di Resort Pemerihan TNBBS dideskripsikan pada Tabel 1. 
Tabel 1. Hasil analisis kandungan Kalsium (Ca), Magnesium (Mg), dan Kalium (K) pada lumpur dan Tanah di Resort Pemerihan TNBBS 2015.

\begin{tabular}{ccllll}
\hline \multirow{2}{*}{ No } & Sumber garam mineral & \multicolumn{3}{c}{ Kadar garam (\%/dry weight) } \\
\cline { 3 - 5 } 1 & & Tanah & Kalsium $(\mathbf{C a})$ & Magnesium $(\mathbf{M g})$ & Kalium $(\mathbf{K})$ \\
2 & Lumpur & 0,190 & 0,013 & 0,158 \\
\hline
\end{tabular}

Sumber: Resphaty dan UPT Laboratorium Terpadu dan Sentra Inovasi Teknologi Universitas Lampung, 2015.

Jumlah garam mineral yang terkandungan pada sample tanah yaitu $\mathrm{Ca}(0,190 \%), \mathrm{Mg}$ $(0,013 \%)$, dan K (0,158\%). Sedangkan pada lumpur Ca $(0.323 \%), \mathrm{Mg}(0,405 \%)$, dan K $(0,233 \%)$. Hasil analisis menunjukan bahwa garam mineral lebih banyak terkandung pada lumpur yang diperoleh secara komposit yaitu lumpur yang berasal dari pinggir sungai, kubangan, dan padang rumput. Gajah lebih sering menggunakan lumpur sebagai sumber garam karena kandungan garam mineral pada lumpur lebih besar dibandingkan dengan tanah. Menurut Blake, Mosquera, Guerra, Loiselle, Romo, dan Swing (2011) tanah yang dikonsumsi oleh satwa pada lokasi tertentu memiliki kandungan garam mineral yang lebih tinggi dibandingkan tanah di lokasi lain.

Hasil analisis kandungan garam di Taman Nasional Way Kambas yang dilakukan oleh Ribai dkk (2012) menunjukkan rata-rata kandungan garam sebesar 0,013\%, kandungan garam terbesar berada di lokasi rawa sebesar 0,016 \%, sehingga gajah yang ada di Way Kambas lebih sering menggaram di lokasi tersebut. Sedangkan hasil analisis kandungan garam mineral di tempat menggaram di Sektor Borju Taman Nasional Danau Kainji Nigeria oleh Lameed dan Adetola (2012) serta persyaratan garam mineral yang harus terpenuhi oleh gajah menurut Dierenfeld (1994) dalam Rode dkk (2006) dideskripsikan pada Tabel 2 berikut.

Tabel 2. Persyaratan garam mineral gajah dan hasil analisis kandungan $\mathrm{Ca}, \mathrm{Mg}$, dan $\mathrm{K}$ pada satlicks di Sektor Borju Taman Nasional Danau Kainji Nigeria.

\begin{tabular}{|c|c|c|c|c|c|}
\hline \multirow{2}{*}{$\begin{array}{c}\text { Jenis garam } \\
\text { Mineral }\end{array}$} & \multirow[t]{2}{*}{ Persyaratan gajah $^{1}$} & \multicolumn{3}{|c|}{ Analisis $\operatorname{garam}^{2}(\% /$ dry weight $)$} & \multirow[b]{2}{*}{ Lokasi 4} \\
\hline & & Lokasi 1 & Lokasi 2 & Lokasi 3 & \\
\hline Kalsium (Ca) & $1,5 \%$ & 1,79 & 3,54 & 1,92 & 1,85 \\
\hline Magnesium (Mg) & $0,1 \%$ & 0,88 & 1,23 & 0,81 & 0,79 \\
\hline Kalium (K) & $0,6 \%$ & 6,76 & 4.46 & 0,79 & 6,95 \\
\hline
\end{tabular}

Sumber: ${ }^{1}$ Dierenfeld (1994); Rode (2006), ${ }^{2}$ Lameed dan Adetola (2012) dengan modifikasi.

Menurut Dierenfeld (1994) dalam Rode dkk (2006) Persayaratan Mg untuk gajah yaitu 0,1\%, K sebesar 0,6\%, dan Ca sebesar 1,5\%. Kebutuhan garam mineral tersebut dipenuhi dari konsumsi tumbuhan pakan, dan dicukupi oleh menggaram. Hasil analisis yang dilakukan Lameed dan Adetola (2012) menunjukkan bahwa kandungan garam pada lokasi menggaram gajah di Sektor Borju Taman Nasional Danau Kainji Nigeria mampu mencukupi kebutuhan mineral satwa liar yang hidup disana. Kekurangan mineral tertentu dalam gajah dapat mempengaruhi pertumbuhan seperti: menyebabkan masalah reproduksi dan menyusui, kekurusan dan kelesuan, menyebabkan pertumbuhan abnormal, kurang nafsu makan, kelainan Zn, anemia, selaput lendir pucat, dan denyut yang tidak beraturan (Asian Nature, 2011). 


\section{KESIMPULAN}

Berdasarkan penelitian yang telah dilakukan maka dapat disimpulkan bahwa perilaku menggaram gajah jantan (Yongki) di Resort Pemerihan TNBBS sebesar 0,08\% dari total analisis waktu perilaku hariannya. Sumber garam yang digunakan yaitu akar dan kulit pohon serta tanah dan lumpur yang berasal dari pinggir sungai, tebing, hutan primer, hutan sekunder dan padang rumput. Menggaram dilakukan dengan cara mengambil langsung dengan belalai lalu dimasukkan ke dalam mulut. Jumlah garam mineral yang terkandung pada sample tanah yaitu $\mathrm{Ca}(0,190 \%) ; \mathrm{Mg}(0,013 \%) ; \mathrm{K}(0,158 \%)$. Pada lumpur yaitu $\mathrm{Ca}(0.323 \%) ; \mathrm{Mg}$ $(0,405 \%)$ dan $\mathrm{K}(0,233 \%)$. Hasil analisis menunjukkan bahwa garam mineral lebih banyak terkandung pada lumpur.

\section{DAFTAR PUSTAKA}

Abdullah, Dahlian, dan Mukhlisin. 2009. Preferensi makan Gajah Sumatera (Elephas Maximus Sumatranus) di Kawasan Hutan Cagar Alam Jantho. Jurnal Biologi Edukasi. $\mathrm{I}(\mathrm{I}): 65-71$.

Asian Nature, 2011. Elephant nutritions. 2011. Diakses pada selasa 3 Februari 2015. http:// www.asiannature.org/know-elephant/elephant-nutrition.

Ayeni, S.O. 1972. Chemical analysis of some soil samples from aatural licks. East Africa Wildlife Journals. 2:16-23.

Blake, J.G., D. Mosquera., J. Guerra., B.A. Loiselle., D. Romo, dan K. Swing. 2011. Mineral licks as diversity hotspots in lowland forest of Eastern Ecuador. Diversity. 3(2):217234.

Drvodelic, N dan J. Cauduro. 2013. Determination of metals in wine using the Agilent 4100 Microwave Plasma-Atomic Emission Spectrometer System. 2013. Diakses pada 27 November 2014. www.chem.agilent.com.

Fadillah, R., D. Yoza, dan E. Sribudiani. 2014. Sebaran dan perkiraan produksi pakan Gajah sumatera (Elephas maximus sumatranus Temminck) di sekitar Duri Kecamatan Mandau Kabupaten Bengkalis. Jurnal Online Mahasiswa Faperta. 1(2).

Hariyanto. 2009. Gajah sumatera. Juli 2009. Diakses pada 22 Mei 2014. http://blogmhariyanto.blogspot.com/2009/07/gajah-sumatera.html.

Komers P.E, F. Messier, dan C.C. Gates. 1992. Search or relax: the case of bachelor wood bison. Behav Ecol Sociobiol. 31(2):195-203.

Lameed A.G, dan J.O. Adetola. 2012. Species-Diversity Utilization of Salt Lick Sites at Borgu Sector of Kainji Lake National Park, Nigeria. Biodiversity Enrichment in a Diverse World. 35-62.

Lekagul, B dan J.A. McNeely. 1977. Mammals of Thailand. The Association for the Conservation of Wildlife. Bangkok.

Mahanani, A.I., I.B. Hendrarto, Dan T.R. Soeprobowati. 2012. Daya dukung habitat Gajah sumatera (Elephas maximus sumatranus Temminck) di Suaka Margasatwa Padang Sugihan Provinsi Sumatera Selatan. Prosiding Seminar Nasional Pengelolaan Sumberdaya Alam Dan Lingkungan. Semarang, 11 September 2012.

Nugraha, N dan Resphaty, D.A. 2015. Peta lokasi menggaram gajah sumatera di Resort Pemerihan Taman Nasional Bukit Barisan Selatan. Tidak dipublikasikan. Bandar Lampung.

Ribai., A. Setiawan, dan A. Darmawan. 2012. Perilaku Menggaram Gajah sumatera (Elephas maximus sumatranus) Di Pusat Konservasi Gajah Taman Nasional Way Kambas. Jurnal Tengkawang. 2(1):1-9. 
Rode, K.D., P.I Chiyo, C.A. Chapman, dan L.R. Mcdowell, 2006. Nutritional Ecology of Elephants in Kibale National Park, Uganda and its Relationship With Crop-Raiding Behavior. Journal of Tropical Ecology (2006) 22:441-449.

Shoshani, J dan J.F. Eisenberg. 1982. Elephas maximus. The American Society of mammalogists. Mammalian Species 182: 1-8.

Sitienei, A.J., G. Jiwen., S.M. Ngene., M.J. De la paix, dan F.K. Waweru. 2011. Analysis in the Concentration, Determination and Comparison of some Mineral Elements in the Natural Salt-Licks Utilized by Elephants: Mt. Elgon National Park Case Study. Advanced material research. (356-360):1796-1800.

Turang, A.C., R. Moningka., B. Kumontoi, dan Sudarti. 2013. Teknik Pengambilan Contoh Tanah Komposit Untuk Uji Tanah. Balai Pengkajian Teknologi Pertanian Sulawesi Utara. Manado.

Resphaty, D.A dan UPT Laboratorium Terpadu dan Sentra Inovasi Teknologi Universitas Lampung. 2015. Laporan Hasil Pengujian Logam Mg, K, Ca. Tidak dipublikasikan. Universitas Lampung. Bandar lampung.

Yudarini, N.D., I.G. Soma, dan S. Widyastuti. 2013. Tingkah Laku Harian Gajah sumatera (Elephas Maximus Sumatranus) di Bali Safari and Marine Park, Gianyar. Indonesia Medicus Veterinus 2013. 2(4): 461- 468 ISSN : 2301-7848. 
Vol. 3 No. 2, Mei 2015 (123-130)

Halaman ini sengaja dikosongkan 